\title{
THE ROLE OF REFLECTING SURFACES IN ACHIEVING A DARK AND LUMINOUS EFFECT FOR VIDA BEKASI MARKETING OFFICE'S WORK-RELATED ACTIVITIES
}

\author{
${ }^{1}$ Edward Pradipta. ${ }^{2}$ Ir. Mira Dewi Pangestu, M.T. \\ ${ }^{1}$ Student in the Bachelor's (S-1) Study Program in Architecture \\ at Parahyangan Catholic University \\ ${ }^{2}$ Senior lecturer in the Bachelor's (S-1) Study Program in Architecture \\ at Parahyangan Catholic University
}

\begin{abstract}
Lighting plays an important role in space formation and supporting activities. The utilization of natural lighting for the sake of saving energy can serve that purpose at noon. In the office, good natural lighting will support effienct use of energy by not using artificial lighting. The particular kind of sunlight that feels comfortable for office use should be the non-direct one which is reflected first. Therefore, the natural lighting design should pay attention to this, from the exterior to the interior elements, especially the reflecting surface providing non-direct sunlight.

As one of Jakarta's satellite cities, Bekasi's development keeps increasing. New housing areas appear and require marketing offices as working areas and for image branding. The marketing office located in Vida Bekasi in East Bekasi uses no artificial lighting at noon. This research discusses what kind of role reflecting surfaces play in achieving a dark and luminous effect for Vida Bekasi marketing office's work-related activities, by focusing on office rooms A and B. Room A on the first floor and room B on the second floor are interesting topics for discussion as they share the reflecting surface element even though the effect differs.

This research can be classified as evaluative-descriptive, employing both the qualitative and quantitative methods. The research started off with interviews conducted with both the architect and the site architect, in addition to literature study, magazine articles, brochures, and internet sources. The calculations were made with a ruler and lux meter, and simulation was conducted with the Velux Daylight Visualizer 3.

The analysis concludes that the reflecting surface configuration ranging from form and color to texture is one of the possible strategies to optimize natural lighting in offices.
\end{abstract}

\section{PERANAN BIDANG REFLEKSI DALAM MEMBENTUK EFEK GELAP-TERANG CAHAYA ALAMI UNTUK AKTIVITAS BEKERJA PADA KANTOR PEMASARAN VIDA BEKASI}

\author{
${ }^{1}$ Edward Pradipta. ${ }^{2}$ Ir. Mira Dewi Pangestu, M.T. \\ ${ }^{1}$ Mahasiswa S1 Program Studi Arsitektur Universitas Katolik Parahyangan. \\ 2 Dosen Pembimbing S1 Program Studi Arsitektur Universitas Katolik Parahyangan.
}

\begin{abstract}
Abstrak- Pencahayaan memiliki peranan penting dalam arsitektur, baik dalam pembentukkan ruang maupun sebagai penunjang aktivitas. Pada bangunan kantor, pencahayaan alami yang memadai tentu akan mendukung efisiensi energi dari sisi penghematan penggunaan cahaya buatan. Cahaya matahari yang nyaman untuk kantor
\end{abstract}

${ }^{1}$ Corresponding Author: edwpdt@hotmail.com 
adalah cahaya matahari tidak langsung yang dipantulkan terlebih dahulu. Dalam pemanfaatannya, proses perancangan pencahayaan alami dalam bangunan perlu diperhatikan mulai dari elemen luar bangunan, hingga elemen dalam bangunan, terutama bidang refleksi yang menghasilkan sinar matahari tidak langsung. Beragam kawasan perumahan baru bermunculan dan memerlukan sebuah kantor pemasaran sebagai kantor pengolahan, sekaligus peningkatan image branding kawasan yang salah satunya adalah Vida Bekasi yang terletak di Bekasi Timur, dimana bangunan tidak memakai pencahayaan buatan sama sekali pada siang hari. Kajian penelitian ini membahas bagaimana peranan bidang refleksi dalam membentuk efek gelap maupun terang untuk aktivitas bekerja kantor pemasaran Vida Bekasi. Penelitian difokuskan terhadap ruang kerja A pada lantai 1 dan B pada lantai 2 yang menarik karena memiliki elemen bidang refleksi sama namun efek yang dihasilkan berbeda. Jenis penelitian ini adalah penelitian deskriptif - evaluatif, dengan pendekatan kuantitatif dan kualitatif. Dimulai dengan wawancara dengan pihak arsitek (Andramatin Architects) dan pihak site architect dari Vida Bekasi, serta studi literatur berbagai sumber artikel majalah, brosur Vida Bekasi, dan melalui internet. Sementara pengukuran dilakukan langsung di lapangan menggunakan meteran dan luxmeter, serta simulasi dengan Velux Daylight Visualizer 3. Ditemukan bahwa konfigurasi bidang refleksi mulai dari bentuk, warna, hingga tekstur adalah salah satu strategi untuk mengoptimalkan pencahayaan alami dalam sebuah ruang kantor.

Kata-kata kunci: pencahayaan alami, bidang refleksi, kantor pemasaran Vida Bekasi

\section{PENDAHULUAN}

\subsection{LATAR BELAKANG PENELITIAN}

Pemanfaatan cahaya alami dalam rangka menghemat energi pada bangunan akan memenuhi dua kebutuhan dasar manusia yaitu kebutuhan visual untuk melihat baik bidang kerja maupun ruangan dan untuk mengalami stimulasi lingkungan dari efek pencahayaan tersebut (Boyce, 1998 dalam IEA, 2000). Terutama Indonesia sebagai negara dengan kondisi geografis pada garis khatulistiwa, ketersediaan cahaya alami relatif stabil sepanjang tahun sehingga potensi terhadap pemanfaatan cahaya alami sangat besar. Cahaya matahari yang nyaman untuk dimanfaatkan harus melalui refleksi sehingga cahaya yang datang tidak secara langsung diterima oleh mata. Sesuai sifat cahaya sebagai gelombang, refleksi cahaya dapat dipengaruhi oleh bidang refleksi bangunan itu sendiri baik dari interior maupun eksterior bangunan. Bidang refleksi eksterior dan interior pun dapat dipengaruhi lagi oleh bentuk bidang, warna, maupun tekstur yang berkaitan dengan material dan finishing yang digunakan. Penggunanan bidang refleksi yang tidak tepat dapat menyebabkan ketidaknyamanan visual baik berupa kurangnya intensitas cahaya dalam ruangan (gelap) ataupun justru intensitas cahaya yang berlebih (silau). Oleh karena itu diperlukan perhatian terhadap bidang refleksi yang digunakan dan faktor refleksi yang dihasilkan oleh setiap bidang tersebut.

Sebagai salah satu kota satelit Jakarta, pembangunan di kawasan Bekasi terus meningkat mengingat sudah terlalu padatnya Jakarta. Beragam kawasan perumahan baru bermunculan dan tentunya diperlukan sebuah kantor pemasaran sebagai kantor pengolahan sekaligus peningkatan image branding kawasan. Salah satu kawasan yang sedang dikembangkan adalah Vida Bekasi yang terletak di Bekasi Timur. Kantor pemasaran Vida Bekasi dirancang oleh arsitek ternama Andra Matin dengan memperhatikan metoda pemanfaatan cahaya alami demi menjaga kenyamanan visual tetap dapat tercapai pada ruangruang di dalam bangunan. 


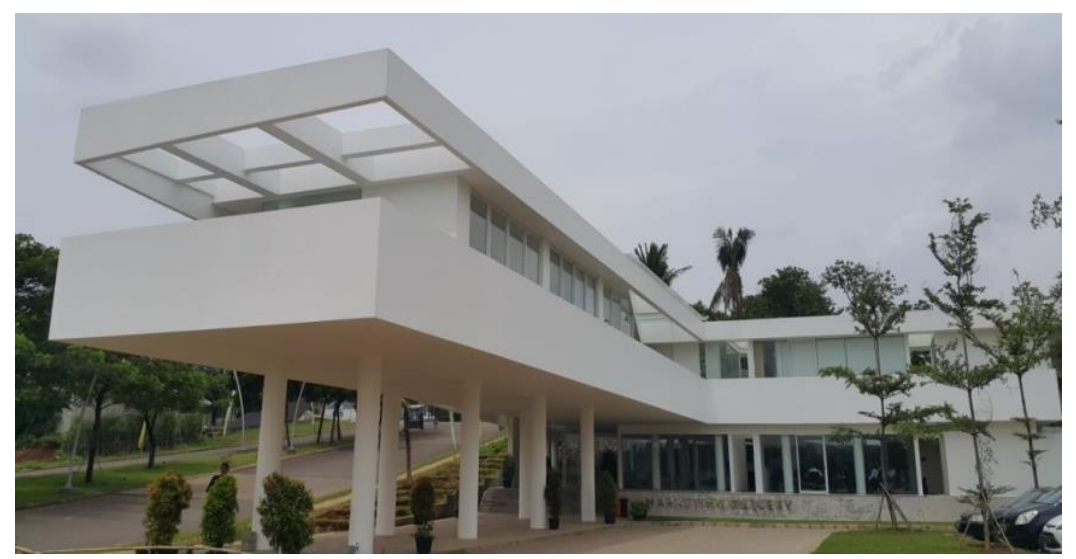

Figur 1. Eksterior Kantor Pemasaran Vida Bekasi

\subsection{PERUMUSAN MASALAH}

Berdasarkan observasi, unit-unit ruang kantor pada kantor pemasaran Vida Bekasi masih memiliki permasalahan kenyamanan visual terkait pencahayaan alami. Fenomena tersebut menunjukkan adanya kontradiksi antara rancangan arsitek dengan hasil yang diperoleh. Dimana sebenarnya arsitek sudah melakukan berbagai upaya agar cahaya alami dapat dimaksimalkan pada bangunan dengan nyaman, namun hasilnya standar kenyamanan visual pada ruang masih belum tercapai. Oleh karena itu, dilakukan penelitian mengenai aplikasi bidang refleksi dan pengaruhnya terhadap tingkat efek gelap terang cahaya alami pada beberapa ruangan di kantor pemasaran Vida Bekasi. Studi kasus ruangan dipilih berdasarkan kriteria pemanfaatan cahaya alami, masalah yang timbul pada ruangan, orientasi matahari, fungsi dan ijin survey untuk melakukan penelitian dan pengukuran.

Untuk melakukan penelitian lebih lanjut, dirumuskan pertanyaan penelitian yang terkait dengan rumusan masalah yaitu bagaimana pengaruh bidang refleksi luar dan dalam terhadap penetrasi cahaya alami ke dalam ruangan, bagaimana pengaruh warna dan tekstur bidang refleksi terhadap cahaya alami di dalam ruangan, dan upaya apa yang dapat dilakukan untuk mengoptimalkan tingkat kenyamanan visual cahaya alami dalam ruangan.

\subsection{TUJUAN PENELITIAN}

Penelitian dilakukan dengan tujuan mengetahui dan memahami pengaruh bidang refleksi luar dan dalam terhadap penetrasi cahaya alami ke dalam ruangan, mengetahui dan memahami pengaruh warna dan tekstur bidang refleksi terhadap cahaya alami di dalam ruangan, memberikan usulan upaya apa yang dapat dilakukan untuk mengoptimalkan tingkat kenyamanan visual cahaya alami dalam ruangan.

\subsection{MANFAAT PENELITIAN}

Manfaat penelitian bagi pihak pengelola adalah mengoptimalkan sistem pencahayaan alami yang sudah ada pada ruang kerja yang dijadikan objek penelitian. Sementara bagii pihak peneliti adalah menambah wawasan dalam dunia arsitektur terutama terkait dengan bidang aplikasi pencahayaan alami pada ruang kerja melalui pembelajaran cara berpikir dan gagasan yang dimiliki arsitek, serta memberikan masukan untuk penelitian sejenis selanjutnya. 


\section{KAJIAN TEORI}

\subsection{PENCAHAYAAN ALAMI PADA KANTOR}

Pemanfaatan cahaya alami dalam kantor harus selalu mengutamakan cahaya bola langit (skylight), karena sinar matahari langsung (sunlight) akan membawa efek panas dan silau yang menyebabkan ketidaknyamanan. Cahaya skylight yang nyaman untuk dimanfaatkan pun diharuskan melalui refleksi sehingga cahaya yang datang tidak secara langsung diterima oleh mata. Sesuai sifat cahaya sebagai gelombang, refleksi cahaya dapat dipengaruhi oleh bidang refleksi bangunan itu sendiri baik dari interior maupun eksterior bangunan.

Kenyamanan bekerja tentu dapat tercapai apabila kenyamanan visual dapat bekerja secara optimal melalui pemenuhan syarat tingkat iluminasi dan kesilauan (Manurung, 2012). Aktivitas dalam kantor yang beragam mulai dari komputer, menulis, membaca, rapat, hingga kegiatan teknis membutuhkan pencahayaan yang berbeda.

Tabel 1

Standar Penerangan (Lux) Pada Kantor

(Sumber: SNI 03-2396-2001)

\begin{tabular}{|c|c|c|c|}
\hline Fungsi Ruangan & $\begin{array}{c}\text { Tingkat } \\
\text { Pencahayaan } \\
\text { (Lux) }\end{array}$ & $\begin{array}{c}\text { Kelompok Renderasi } \\
\text { Warna }\end{array}$ & Keterangan \\
\hline \multicolumn{4}{|c|}{ Perkantoran : } \\
\hline Ruang Direktur & 350 & 1 atau 2 & \\
\hline Ruang Kerja & 350 & 1 atau 2 & \\
\hline Ruang Komputer & 350 & 1 atau 2 & $\begin{array}{c}\text { Gunakan pencahayaan } \\
\text { setempat pada meja } \\
\text { gambar }\end{array}$ \\
\hline Ruang Rapat & 300 & 1 atau 2 & \\
\hline Ruang Gambar & 750 & 1 atau 2 & \\
\hline Gudang Arsip & 150 & 3 atau 4 & 1 atau 2 \\
\hline Ruang Arsip Aktif & 350 &
\end{tabular}

\subsection{PENCAHAYAAN ALAMI}

Pencahayaan alami adalah pemanfaatan cahaya yang berasal dari benda penerang alam seperti matahari, bulan, dan bintang sebagai pencahayaan ruang. Cahaya sebagai gelombang akan mengalami polarisasi (Marcelo, 1992). Polarisasi cahaya adalah pembatasan atau pengutuban arah getaran gelombang transversal menjadi satu arah getar tertentu. Polarisasi cahaya dapat dibagi menjadi beberapa prinsip perjalanan cahaya yaitu:

(1) Refleksi: peristiwa terpantulnya cahaya bila mengenai suatu permukaan. Jumlah cahaya yang direfleksikan permukaan ditunjukkan dengan besaran factor refleksi (p) yaitu perbandingan fluks cahaya yang dipantulkan dibandingkan dengan fluks cahaya yang diterima permukaan. 

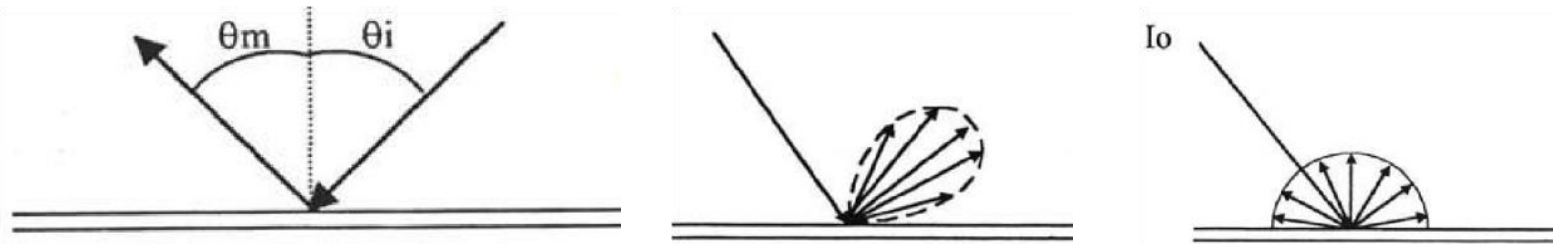

Figur 2. Refleksi Spekular, Refleksi Menyebar, \& Refleksi Difus

(Sumber: Marcelo, 1992)

(2) Absorpsi: peristiwa terserapnya cahaya oleh suatu bahan. Harga absortansi tergantung karakteristik bahan. Penyerapan cahaya oleh bahan dapat lihat pada faktor absorbsi $(\alpha)$ bahan yaitu perbandingan fluks cahaya yang diserap dengan fluks cahaya yang datang.

(3) Transmisi: peristiwa penjalaran cahaya melewati suatu medium ke medium yang lain. Cahaya akan mengalami pembiasan bila melewati medium yang mempunyai indeks bias yang berbeda. Cahaya akan dibiaskan mendekati garis normal bila memasuki medium dengan indeks bias lebih tinggi dan akan menjauhi gans normal bila memasuki medium dengan indeks bias lebih rendah. Pada peristiwa transmisi diperoleh faktor transmisi $(\tau)$ yaitu fluks cahaya yang ditransmisikan dibanding dengan fluks cahaya yang datang pada bahan tersebut. Transmisi dapat dikelompokkan menjadi transmisi spekular, transmisi menyebar, dan transmisi difus.

\subsection{FAKTOR REFLEKSI}

Cahaya alami dapat diuraikan menjadi beberapa unsur berdasarkan arah sinar langsung dan pantulannya.

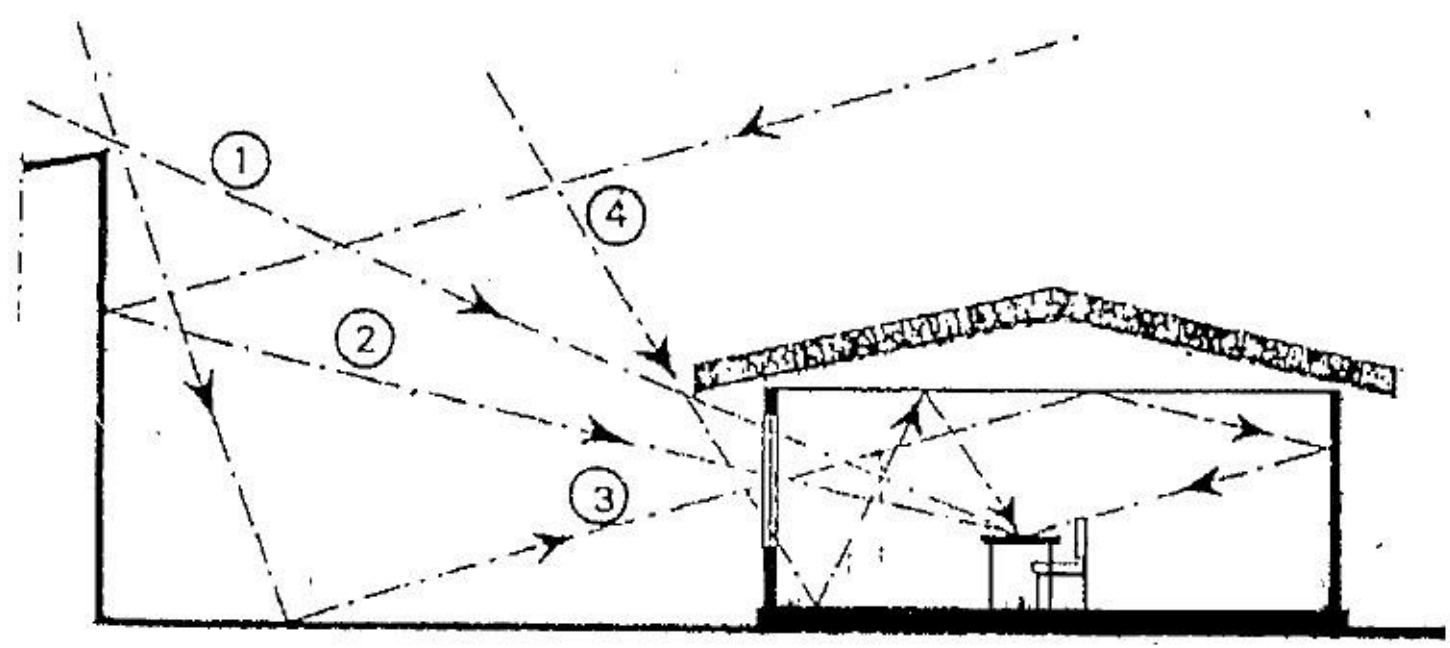

1. cahaya langsung dari matahari pada bidang kerja

2. cahaya pantulan dari benda-benda sekitar

3. calıaya pantulan dari halaman, yang kemudian dipantulkan oleh langitlangit atau dinding ke arah bidang kerja

4. cahaya yang jatuh di lantai dan dipantulkan lagi oleh langit-langit

Figur 3. Unsur Pencahayaan Alami

(Sumber: Mangunwijaya, 2000) 
(1) Faktor Refleksi Luar (Bidang Refleksi Eksterior): dipengaruhi oleh ukuran lubang cahaya, ukuran penghalang, reflektansi cahaya dari permukaan penghalang, posisi titik tersebut pada bidang kerja. Namun tidak dipengaruhi oleh reflektansi cahaya dari permukaan dalam ruangan.

(2) Faktor Refleksi Dalam (Bidang Refleksi Interior): mempengaruhi cahaya yang dipantulkan pada refleksi dalam dapat berupa cahaya langsung dari langit maupun cahaya yang terlebih dahulu dipantulkan oleh permukaan luar, baik berupa penghalang ataupun permukaan tanah di sekitar lubang cahaya.

Pengaruh Keadaan Bidang Refleksi:

(1) Bentuk: Daya pantulan dari permukaan interior sangat penting dalam meningkatkan komponen yang dipantulkan dari faktor cahaya pada sinang hari. Permukaan ini bisa berupa lantai ketika cahaya datang langsung dari langit, ataupun plafon jika cahaya dipantulkan dari permukaan tanah eksterior. Bidang plafon merupakan bidang yang paling berperan dalam memantulkan cahaya dai luar. Selain plafon terdapat bidang dinding belakang, dinding samping, dan bidang lantai yang mendukung refleksi dalam ruangan. Sehingga dari tabel dan kesimpulan diatas, penggunaan warna yang tepat adalah warna cerah pada bidang langit-langit dan warna gelap untuk bidang lantai.

(2) Warna: umumnya dapat dikatakan bahwa semakin muda warna bidang ruangan (dinding, lantai, plafon, perabot, dsb) ataupun mendekati putih, pencahayaan ruangan semakin baik dan ekonomis karena jumlah cahaya yang dipantulkan kembali oleh bidang tersebut berjumlah banyak. Namun tetap perlu diperhatikan walaupun bidang refleksi yang berkilau memantulkan cahaya dengan baik, tapi dapat menyebabkan ketidaknyamanan visual pada mata. Contohnya pada lantai ruangan yang bila warnanya dibuat terlalu muda akan menyebabkan gangguan visual.

(3) Tekstur: berkaitan erat dengan material yang akan dipakai sebagai finishing bidang refleksi. Dalam kaitannya dengan pencahayaan, tekstur yang licin akan menghasilkan pantulan cahaya yang lebih maksimal. Sedangkan tekstur kasar ataupun matte akan lebih memencarkan pantulan cahaya

(difus). Karena itu seringkali karpet dipakai pada lantai berwarna cerah dan tekstur licin untuk membaurkan sinar cahaya. Dapat juga membuat dinding dengan tekstur kasar atau cat dengan tekstur matte yang akan lebih membaurkan cahaya.

\section{ANALISA}

\subsection{METODOLOGI PENELITIAN}

\subsubsection{JENIS PENELITIAN}

Jenis penelitian ini adalah penelitian deskriptif - evaluatif, dengan pendekatan kuantitatif dan kualitatif. Penelitian akan menjabarkan faktor apa yang membentuk efek gelap terang cahaya alami pada kantor pemasaran Vida Bekasi terutama terkait dengan bidang refleksi pada bangunan tersebut. Hasil pemaparan data tersebut kemudian dianalisis dan dievaluasi dengan cara membandingkan data studi kasus (kuantitatif) dan didukung oleh hasil angket yang ditujukan terutama kepada pengguna ruangan (kualitatif).

\subsubsection{TEMPAT DAN WAKTU PENELITIAN}



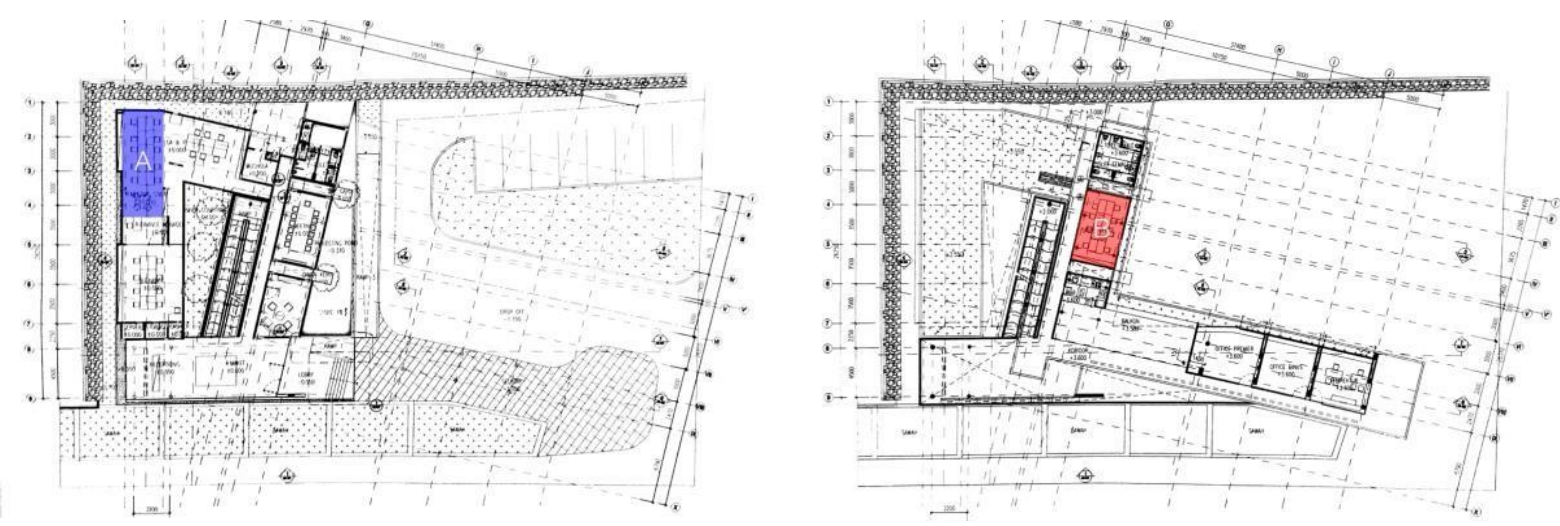

Figur 4. Ruang Penelitian

Ruang kerja A pada lantai 1 dipilih karena sudah menerapkan metode pemasukan cahaya namun secara kualitas masih memiliki suasana suram. Sementara ruang kerja B pada lantai 2 dipilih karena sudah menerapkan metode antisipasi silau. Waktu pengumpulan data, pengamatan, dan pengukuran pada unit ruang kerja yang menjadi studi kasus berlangsung antara bulan Januari hingga Maret. Wawancara kepada pengguna dan arsitek serta observasi objek studi dilakukan pada bulan Febuari. Pengukuran di lokasi studi akan dilakukan pada awal Maret. Sedangkan waktu pengolahan data dan analisis berlangsung antara pertengahan Maret hingga Mei.
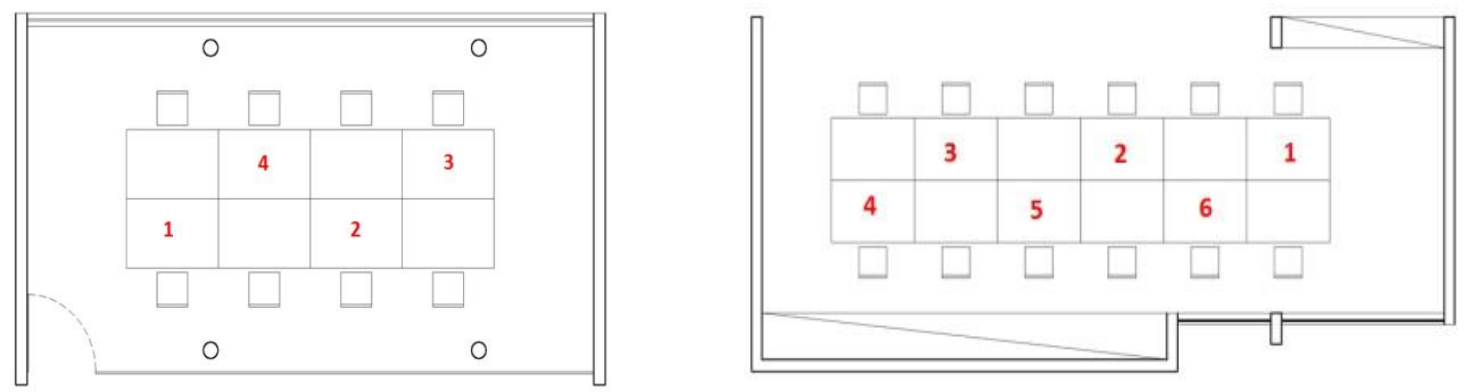

Figur 5. Titik Ukur

\subsubsection{TEKNIK PENGUMPULAN DAN ANALISA DATA}

Dimulai dengan wawancara dengan pihak arsitek (Andramatin Architects) dan pihak site architect dari Vida Bekasi dan studi literatur berbagai sumber artikel pada majalah, brosur Vida Bekasi, dan melalui internet misalnya Google Maps. Gambar kerja dari biro Andramatin Architects dan Gunas Land selaku pengembang dari kawasan Vida Bekasi juga digunakan untuk analisis. Sementara pengukuran dilakukan langsung di lapangan menggunakan meteran dan luxmeter. Velux Daylight Visualizer 3 digunakan untuk analisa simulasi.

Analisis dalam penelitian ini dibagi menjadi sejumlah tahap untuk menjawab pertanyaan penelitian yaitu kondisi lingkungan sekitar, pengukuran intensitas, analisa komponen bidang refleksi, analisa material bidang refleksi, dan upaya optimalisasi cahaya alami pada ruangan. Teknik pengambilan kesimpulan menggunakan pendekatan deduktif dimana penarikan kesimpulan berawal dari hal yang umum menuju hal yang khusus dengan penyajian jenis sebab-akibat yang diawali sebab-sebab yang kemudian diikuti oleh beberapa akibat untuk memperkuat pernyataan dan menjawab pertanyaan penelitian sehingga dapat diperoleh akibat apa yang dihasilkan dan upaya apa yang dapat dilakukan untuk mengoptimalkan. 


\subsection{ANALISA}

\subsubsection{LINGKUNGAN SEKITAR}
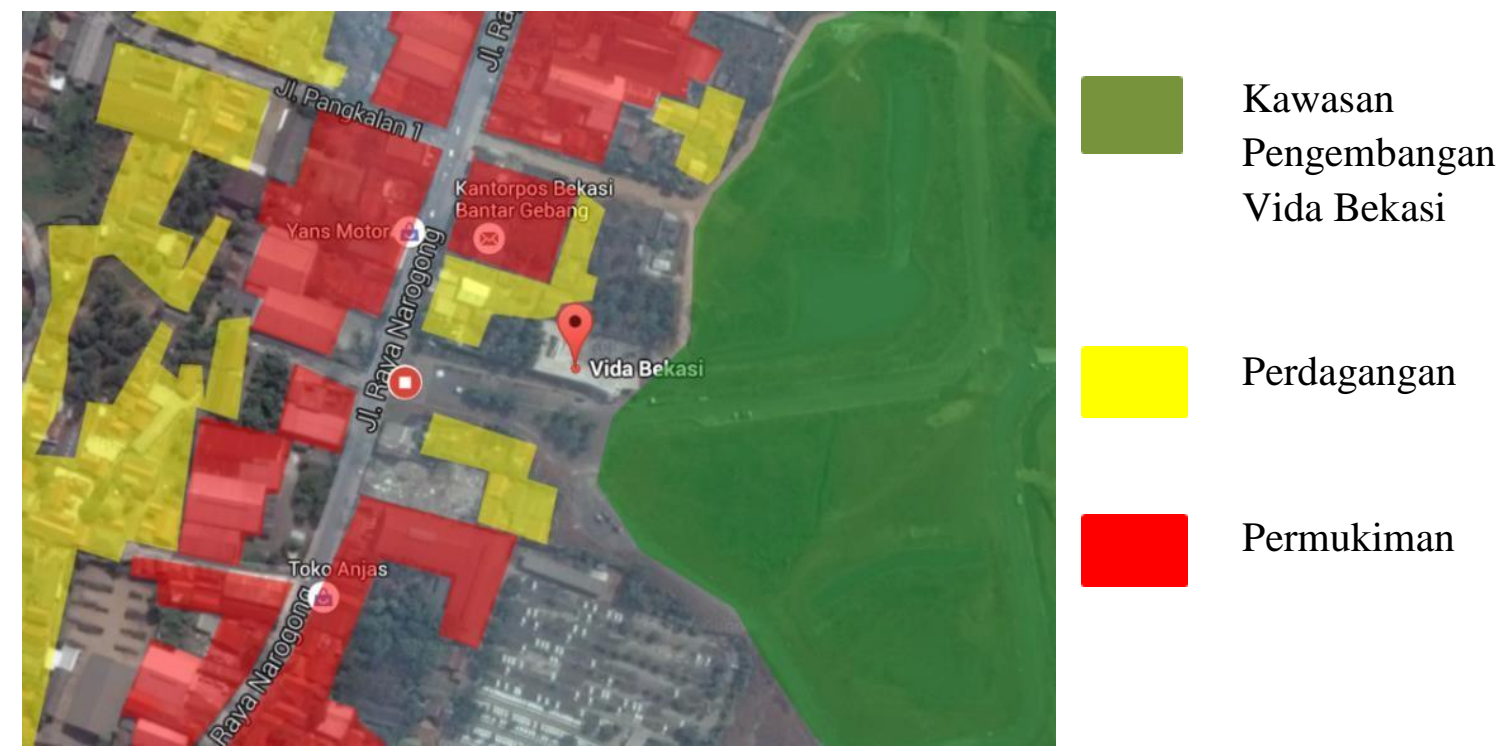

Figur 6. Fungsi Sekitar Kawasan

Kondisi lingkungan kantor pemasaran Vida Bekasi bagian timur masih cenderung kosong dengan tanah disekitar bangunan berupa kawasan pengembangan menjadi potensi sehingga dapat cahaya matahari dari sisi timur dapat dikatakan dapat masuk ke dalam bangunan dalam jumlah besar. Perbedaan ketinggian tanah antara kantor pemasaran Vida Bekasi dan tetangga pada bagian barat dan utara diatasi dengan membuat celah sehingga menjadi potensi tersendiri bagi cahaya untuk masuk ke dalam bangunan dari arah barat namun dalam jumlah yang relatif minim.
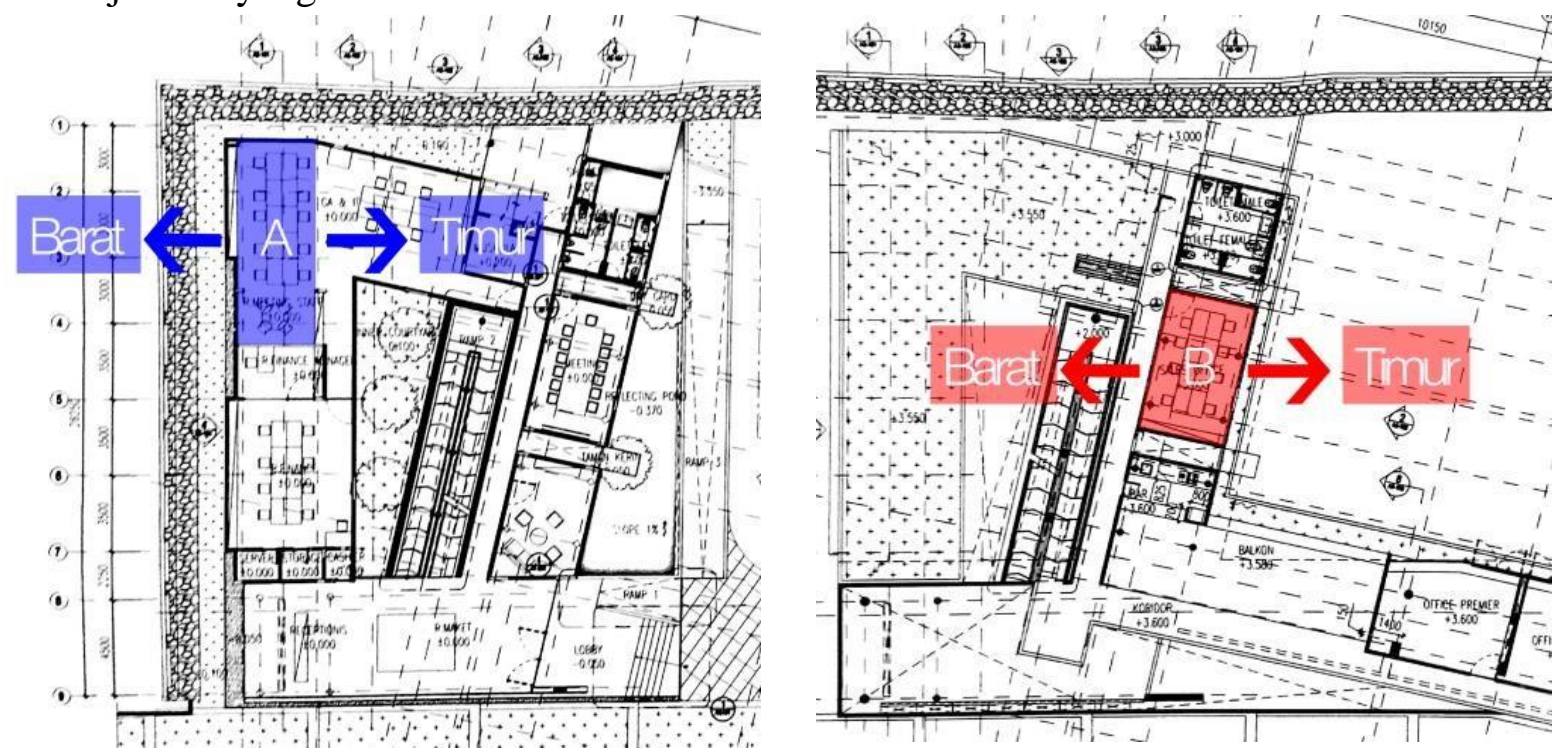

Figur 7. Orientasi Ruang Penelitian 
Orientasi bangunan cenderung miring \pm $10^{0}$ dari arah utara dengan dominasi arah bukaan barat dan timur bangunan. Peletakkan bukaan tersebut akan mendatangkan keuntungan bagi cahaya alami untuk dapat masuk ke dalam ruangan sehingga pencahayaan alami ruangan sangat maksimal. Namun kerugiannya adalah munculnya silau pada bangunan yang seharusnya sesuai teori cenderung sudah diminimalisir dengan adanya teritis yang sesuai dengan teori antisipasi silau pada bangunan.

Bulan Maret dipilih sebagai bulan kritis untuk mewakili penelitian ini karena jalur pergerakan matahari berada pada kurang lebih tepat poros timur-barat kantor pemasaran Vida

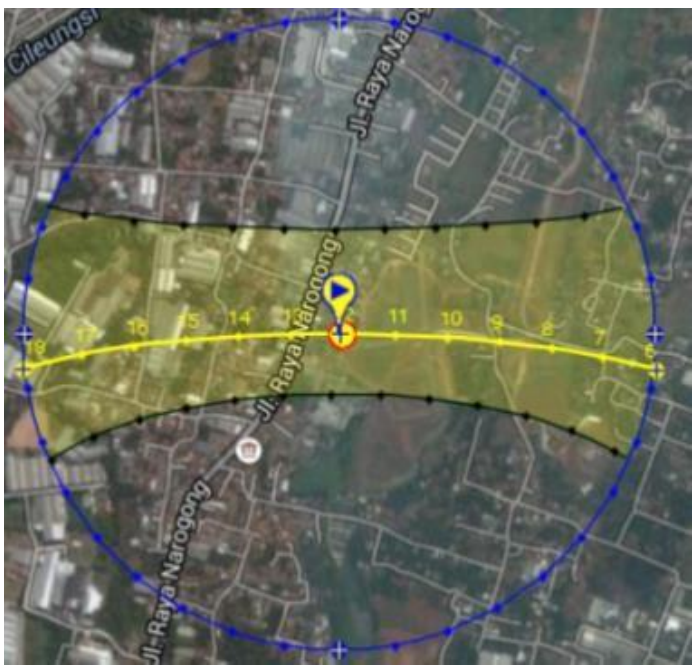

Figur 8. Pergerakan Matahari Maret Bekasi. Hal ini mendukung intensitas cahaya matahari yang masuk ke dalam bangunan secara maksimal. Selain itu bulan Maret juga merupakan bulan dimana Indonesia sudah memasuki musim kemarau sehingga pengukuran langsung di lapangan tidak akan diganggu faktor cuaca dimana matahari terhalang awan sehingga menyebabkan pengukuran menjadi tidak maksimal. Sesuai dengan jangka waktu penelitian, pengukuran manual pun memang dilaksanakan pada bulan Maret.

\subsubsection{RUANG A}
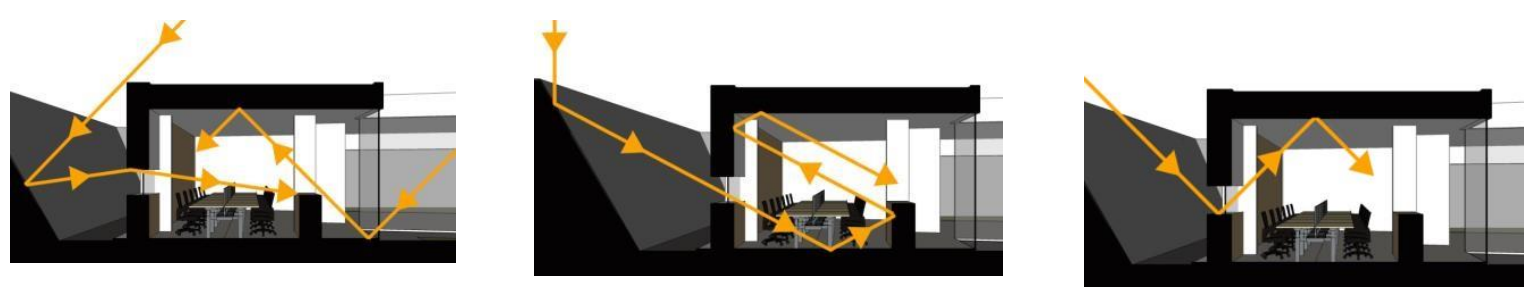

Figur 9. Skema Pantulan Potongan 1 Ruang A Pukul 09.00, 12.00, \& 15.00
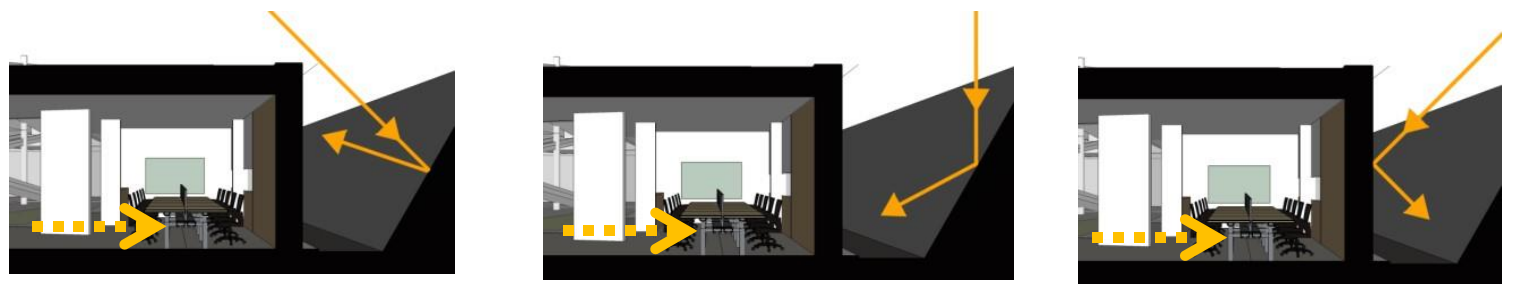

Figur 10. Skema Pantulan Potongan 2 Ruang A Pukul 09.00, 12.00, \& 15.00

Bentuk komponen bidang refleksi eksterior ruang A sudah cukup berperan dalam menghantarkan cahaya alami masuk ke dalam bangunan baik pukul 09.00, 12.00, hingga 15.00. Teknik lightwell berbentuk inner court ditengah bangunan sangat membantu penetrasi cahaya matahari masuk ke dalam ruang A yang terdapat di lantai bawah dari arah timur. Teknik lightwell pada bagian barat ruang A juga berperan untuk memasukkan cahaya alami menuju ruangan dari area barat. Dari analisis skema pantulan cahaya matahari, dinding penahan tanah yang berbentuk miring sangat membantu memantulkan cahaya alami masuk ke dalam ruangan. 
Namun efektifitas bentuk komponen bidang refleksi eksterior tidak didukung oleh konfigurasi lubang cahaya yang efektif. Potensi pantulan cahaya alami dari lightwell bagian barat tidak dapat masuk ke dalam bangunan secara maksimal karena terhalang oleh komponen dinding yang masif dan ukuran lubang cahaya yang kecil.

Tabel 2

Pengukuran Daya Pantul Bidang Refleksi Ruang A

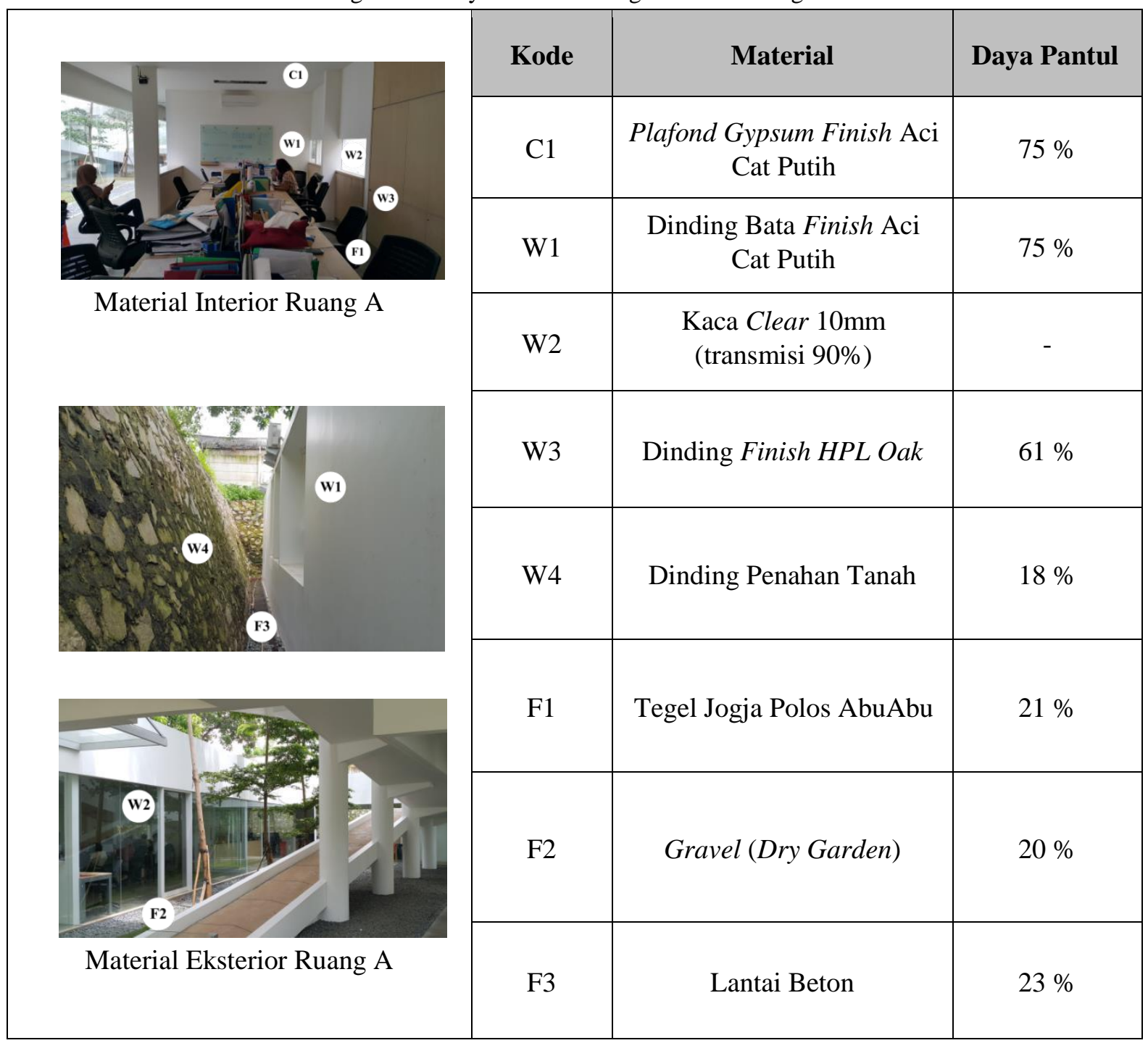

Material dinding penahan tanah yang terbuat dari batu alam pada eksterior ruangan tidak efektif untuk memantulkan cahaya karena memiliki daya pantul yang relatif kecil senilai 18\%. Padahal melanjutkan dari kesimpulan sebelumnya, dinding penahan tanah sebagai bidang refleksi eksterior memiliki kontribusi signifikan dibuktikan dari skema pemantulan cahaya yang telah dilakukan.

Sementara, material finish aci cat putih pada plafon dan dinding sudah tepat untuk memaksimalkan pemantulan cahaya alami dalam ruangan. Material tersebut memiliki daya pantul senilai $75 \%$ sesuai teori dimana warna putih memiliki daya pantul tinggi dengan tekstur matte yang memiliki daya pantul sedang. Penggunaan material dengan daya pantul tinggi ini juga sudah tepat digunakan pada bidang refleksi plafon dan dinding yang sesuai teori memiliki kontribusi pemantulan cahaya tinggi dalam ruangan. Sedangkan penggunaan material tegel 
jogja abu-abu yang cenderung gelap pada lantai juga sudah tepat untuk meminimalisir efek silau pada ruangan sekaligus tidak besarnya kontribusi pemantulan cahaya dari bidang refleksi lantai.

Upaya yang pertama dimulai dari eksterior ruangan yaitu pergantian material bidang refleksi dinding penahan tanah pada lightwell bagian barat ruangan. Tujuannya adalah untuk meningkatkan daya pantul menjadi lebih dari $18 \%$. Sesuai dengan analisis penyesuaian warna dan tekstur maka dipilih tekstur dari acian agar pengerjaan mudah dengan finish tekstur licin sehingga meningkatkan daya pantul bidang refleksi dinding penahan tanah. Optimalisasi dari warna dapat dilakukan dengan finsih cat glossy putih agar daya pantul warna juga meningkat. Sehingga daya pantul bidang refleksi W4 dapat meningkat dari $18 \%$ hingga mencapai $75 \%$. Pada hasil intensitas cahaya ruangan dan kemerataan distribusi cahaya melalui Velux, terlihat pengukuran intensitas cahaya pada setiap titik ukur meningkat cukup jauh namun masih sangat kurang dari standar ketentuan SNI untuk ruang komputer senilai 350 lux. Sehingga upaya kedua masih diperlukan.

Upaya yang kedua masuk ke komponen interior ruangan dengan pergantian bentuk komponen bidang refleksi ruangan pada sisi barat. Tujuannya adalah meningkatkan cahaya matahari yang masuk untuk direfleksikan di dalam ruangan melalui perombakan komponen dinding bagian barat dan meneruskan lubang cahaya yang sudah ada. Untuk memaksimalkan potensi tersebut pergantian material bidang refleksi ditding penahan tanah tetap diaplikasikan pada upaya ini. Hasilnya adalah upaya ini terbukti mampu memaksimalkan pencahayaan dari sisi barat ruangan yang sebelumnya belum diaplikasikan ke dalam bangunan.

Upaya kedua tetap dipilih karena lebih efektif memasukkan cahaya ke dalam ruangan. Tidak meratanya intensitas cahaya pada kedua sisi meja kerja dapat ditolerir mengingat dimensi batas timur dan barat yang memang berbeda. Selain itu hasil kuesioner memperkuat bahwa sebenarnya masih $60 \%$ responden yang merasa nyaman bekerja pada ruang tersebut meskipun sebenarnya gelap.

Tabel 3

Hasil Perhitungan Simulasi Option 2 Ruang A

\begin{tabular}{|c|c|c|c|}
\hline & 09.00 & 12.00 & \\
\hline Titik & Intensitas Pk.09.00 & Intensitas Pk.12.00 & Intensitas Pk.15.00 \\
\hline 1 & 198,9 & 213,3 & 99,3 \\
\hline 2 & 178,7 & 222,6 & 100,9 \\
\hline 3 & 184,5 & 232,5 & 163,5 \\
\hline 4 & 441,0 & 555 & 420,3 \\
\hline
\end{tabular}




\begin{tabular}{|l|l|l|l|}
\hline 5 & 456,4 & 526,8 & 393,2 \\
\hline 6 & 422,5 & 481,2 & 369,7 \\
\hline
\end{tabular}

\subsubsection{RUANG B}
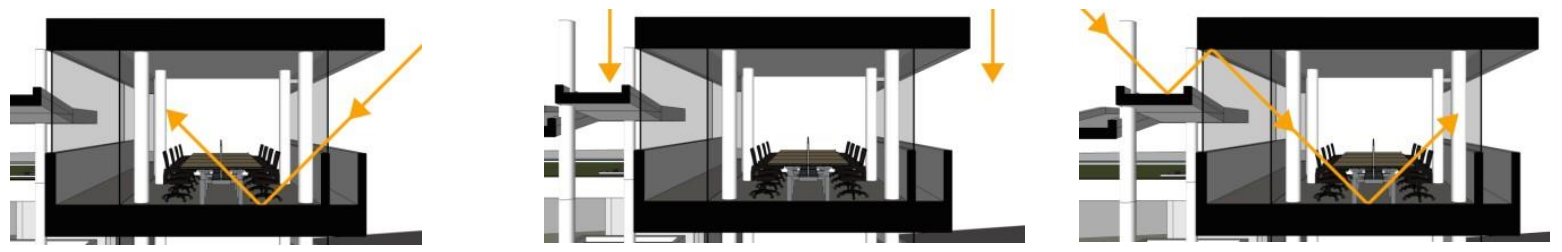

Figur 11. Skema Pantulan Potongan 1 Ruang B Pukul 09.00, 12.00, \& 15.00
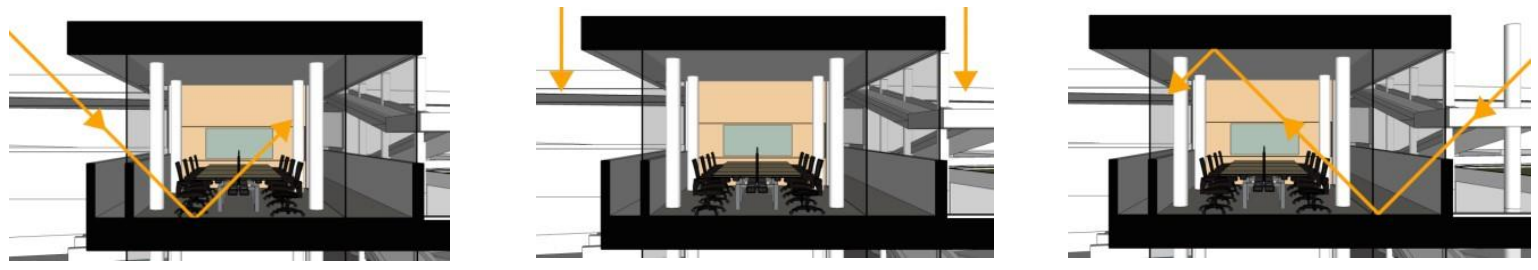

Figur 12. Skema Pantulan Potongan 2 Ruang B Pukul 09.00, 12.00, \& 15.00

Bentuk komponen bidang refleksi eksterior ruang B sudah cukup berperan dalam meminimalisir cahaya. Teritis pada komponen eksterior bagian timur berperan mereduksi cahaya matahari masuk ke dalam ruangan. Konfigurasi koridor sirkulasi pada bagian barat ruang A juga berfungsi sekaligus sebagai pereduksi cahaya. Selain itu, ramp pada sisi barat ruangan dapat berfungsi sebagai pereduksi cahaya matahari yang akan ditransmisikan melalui lubang cahaya pada pukul 15.00. Sementara dari sisi refleksi interior ruang B, komponen lubang cahaya penuh pada sisi timur dan barat mengakibatkan terlalu maksimalnya cahaya matahari yang masuk ke dalama ruang B. Adanya komponen dinding masif setinggi 1 meter pada sisi timur belum cukup berpengaruh untuk mereduksi cahaya matahari untuk masuk ke dalam ruangan.

Tabel 4

Pengukuran Daya Pantul Bidang Refleksi Ruang A

\begin{tabular}{|c|c|c|c|}
\hline & Kode & Material & Daya Pantul \\
\cline { 2 - 4 } & $\mathrm{C} 1$ & $\begin{array}{c}\text { Plafond Gypsum Finish Aci } \\
\text { Cat Putih }\end{array}$ & $75 \%$ \\
\hline $\mathrm{W} 1$ & $\begin{array}{c}\text { Dinding Bata Finish Aci } \\
\text { Cat Putih }\end{array}$ & $75 \%$ \\
\hline $\mathrm{W} 2$ & $\begin{array}{c}\text { Kaca Clear 10mm } \\
\text { (transmisi 90\%) }\end{array}$ & - \\
\hline
\end{tabular}




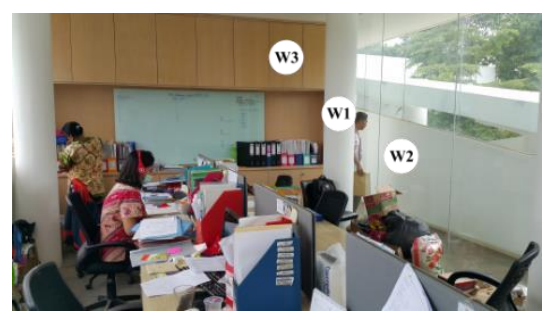

Material Interior Ruang A

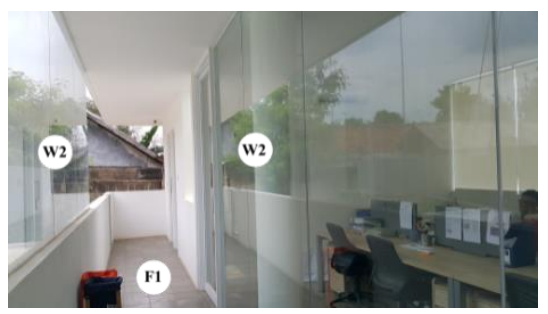

Material Eksterior Ruang B

\begin{tabular}{|c|c|c|}
\hline W3 & Dinding Finish HPL Oak & $61 \%$ \\
\hline W4 & Dinding Penahan Tanah & $18 \%$ \\
\hline F1 & Tegel Jogja Polos AbuAbu & $21 \%$ \\
\hline F2 & Gravel (Dry Garden) & $20 \%$ \\
\hline F3 & Lantai Beton & $23 \%$ \\
& & \\
& & \\
\end{tabular}

Penggunaan material finish aci cat putih pada plafon dan dinding serta penggunaan material HPL Oak pada ruangan ini tidak tepat. Material finish aci cat putih tersebut memiliki daya pantul senilai $75 \%$ sesuai teori dimana warna putih memiliki daya pantul tinggi dengan tekstur matte yang memiliki daya pantul sedang. Sedangkan material HPL Oak memiliki daya pantul $61 \%$. Penggunaan material tersebut pada bidang refleksi plafon dan dinding yang sesuai teori memiliki kontribusi pemantulan cahaya tinggi dalam ruangan justru akan membuat ruangan semakin terang dengan pemantulan maksimal. Sedangkan penggunaan material tegel jogja abu-abu yang cenderung gelap pada lantai sudah tepat untuk meminimalisir efek silau pada ruangan sekaligus tidak besarnya kontribusi pemantulan cahaya dari bidang refleksi lantai.

Tabel 5

Hasil Perhitungan Simulasi Option 1 Ruang B

\begin{tabular}{|c|c|c|c|}
\hline & elum & 12.00 & 15.00 \\
\hline Titik & Intensitas Pk.09.00 & Intensitas Pk.12.00 & Intensitas Pk.15.00 \\
\hline 1 & 336,3 & 366,6 & 361,3 \\
\hline 2 & 359,4 & 366,5 & 347,3 \\
\hline 3 & 375,1 & 462,4 & 402,1 \\
\hline 4 & 395,3 & 522,2 & 564,6 \\
\hline
\end{tabular}


Upaya yang pertama dimulai dari pergantian material bidang refleksi finish aci cat putih dan HPL Oak pada komponen bidang refleksi dinding dan plafon ruangan dengan tujuan memperkecil daya pantul agar cahaya yang masuk ke dalam ruangan berkurang. Agar cahaya yang masuk ke dalam ruangan berkurang dan tidak menyebabkan intensitas cahaya berlebih, maka diperlukan optimalisasi dengan tekstur yang lebih kasar, karena sesuai dengan teori, tekstur yang kasar akan merefleksikan cahaya secara difus. Selain itu warna juga dipilih agar lebih tua dari warna putih agar daya pantulnya berkurang. Material yang dipilih adalah finish aci yang tekstur matte dengan warna abu-abu muda. Sementara pergantian material pada HPL Oak menajdi HPL dengan tekstur lebih kasar sehingga pemantulan cahaya dapat diminimalisir dengan pemantulan yang difus.

Hasilnya adalah pengukuran intensitas cahaya pada setiap titik ukur menurun jauh. Data ini menunjukkan bahwa memang pergantian material pada bidang refleksi berpengaruh pada tingkat intensitas cahaya matahari di dalam ruangan. Koridor pada sisi barat ruangan yang memiliki dimensi lebih besar dengan bidang transparan menyebabkan hasil pada titik ukur 1 dan 2 secara keseluruhan lebih kecil daripada titik ukur 3 dan 4 yang berada pada sisi timur dengan dimensi teritis yang lebih kecil dari koridor barat. Hal ini mengakibatkan tidak memungkinkannya distribusi intensitas cahaya pada setiap titik ukur yang sama. Selain itu perlu diingat kembali bahwa penggunaan cahaya alami memang tidak dapat diandalkan sepenuhnya untuk pemerataan cahaya di dalam ruangan karena sifatnya yang tidak tetap dan berubah tergantung cuaca. Namun secara keseluruhan, data sudah menunjukkan keberadaan hasil pengukuran berkisar diantara standar optimum 350 lux oleh SNI. Dengan demikian, upaya kedua untuk merombak bentuk dari bidang refleksi 2 tidak lagi diperlukan dengan pertimbangan sulitnya pekerjaan yang akan dilakukan dan ada kemungkinan berubahnya ekspresi fasad bangunan yang seharusnya sudah menjadi konsep dan pemikiran dari arsitek.

\section{KESIMPULAN}

\subsection{KESIMPULAN}

Dari poin-poin jawaban atas pertanyaan penelitian dapat ditarik kesimpulan mengenai peranan bidang refleksi dalam membentuk efek gelap-terang cahaya alami untuk aktivitas bekerja kantor pemasaran Vida Bekasi, yaitu:

(1) Lingkungan sekitar bangunan mempengaruhi banyaknya cahaya yang masuk ke dalam bangunan. Lingkungan sekitar yang padat atau lebih tinggi dari tanah bangunan akan menyebabkan berkurangnya cahaya yang masuk dikarenakan adanya pantulan terlebih dahulu dari lingkungan tersebut. Sedangkan lingkungan yang masih kosong tanpa adanya bangunan lain di sekitarnya akan menyebabkan banyaknya cahaya yang masuk ke dalam bangunan.

(2) Orientasi bangunan memiliki peranan dalam pencahayaan dalam bangunan. Peletakkan bukaan pada bagian barat dan timur akan memaksimalkan cahaya yang dapat dipantulkan masuk ke dalam bangunan namun dengan konsekuensi silau karena adanya cahaya matahari langsung yang juga masuk. Karena itu dibutuhkan antisipasi untuk masalah tersebut.

(3) Pergerakan matahari perlu diperhatikan dalam perancangan pencahayaan alami dalam ruangan. Melalui pengamatan gerakan matahari tersebut, dapat diketahui kapan waktu-waktu yang tepat untuk memasukkan cahaya alami ke dalam bangunan. Selain itu, analisa gerakan matahari juga dapat menjadi acuan peletakkan bidang refleksi sebagai pemantul cahaya masuk ke dalam ruangan. 
(3) Bidang refleksi luar memiliki pengaruh dalam penetrasi cahaya alami ke dalam bangunan. Adanya bidang miring pada eksterior ruangan dapat memaksimalkan pemantulan cahaya untuk masuk kedalam ruangan serta menjadi salah satu upaya untuk memaksimalkan pencahayaan pada ruang lantai bawah. Selain teritis, koridor sebagai bidang refleksi juga dapat berperan sebagai pereduksi cahaya alami yang masuk ke dalam ruangan

(4) Bidang refleksi dalam memiliki peranan untuk meneruskan pantulan cahaya alami yang masuk melalui lubang cahaya dengan distribusi cahaya lebih merata. Refleksi plafon dan dinding memiliki kontribusi besar dalam faktor refleksi dalam ruangan. Sementara bidang refleksi lantai memiliki kontribusi rendah dalam distribusi cahaya ruangan.

(5) Pemilihan material dalam kajian tekstur berpengaruh dalam pemerataan distribrusi cahaya dalam ruangan. Material kasar akan menghasilkan pantulan menyebar atau difus. Aplikasinya akan membantu mengurangi efek silau dan mereduksi cahaya matahari dalam ruangan. Sementara material dengan tekstur licin akan menghasilkan refleksi spekular sehingga cahaya matahari dalam ruangan lebih maksimal.

(6) Warna material juga memiliki peranan dalam distribusi cahaya dalam ruangan. Warna yang cenderung muda akan menghasilkan daya pantul material yang maksimal. Sementara warna yang cenderung gelap akan menghasilkan daya pantul material yang lemah karena sebagaian besar cahaya justru diserap oleh bidang tersebut.

\subsection{SARAN}

Manfaat dari penelitian ini ditujukan sebagai masukan bagi pihak pengelola kantor pemasaran Vida Bekasi dan pengguna ruangan dalam hal ini PT. Gunas Land dalam mengoptimalkan pemanfaatan cahaya alami di siang hari. Serta bagi pihak peneliti selanjutnya dengan arah dan studi yang serupa.

\subsubsection{BAGI PIHAK PENGELOLA DAN PENGGUNA}

Berdasarkan hasil penelitian yang dilakukan mengenai bidang refleksi dalam pemanfaatan cahaya alami dalam ruang kerja, serta mengacu pada beberapa kesimpulan yang telah ditarik, maka diberikan beberapa saran untuk mengoptimalisasikan kondisi pemanfaatan pencahayaan alami pada kantor pemasaran Vida Bekasi sebagai berikut:

(1) Pada ruang A saran pertama dimulai dari eksterior ruangan yaitu pergantian material bidang refleksi dinding penahan tanah bagian barat ruangan menjadi tekstur licin dan warna putih agar daya pantul menjadi maksimal.

(2) Saran yang kedua pada ruang A adalah pergantian bentuk komponen bidang refleksi melalui perombakan komponen dinding bagian barat dan penambahan lubang cahaya untuk memaksimalkan potensi bidang refleksi dinding penahan tanah

(3) Saran untuk ruang B adalah pergantian material bidang refleksi finish aci cat putih pada bidang refleksi dinding dan plafon ruangan dengan tekstur yang lebih kasar berupa finish aci tekstur matte dengan warna abu-abu muda. Sementara material HPL Oak menajdi HPL dengan tekstur lebih kasar.

\subsubsection{BAGI PENELITIAN SEJENIS}

Penelitian tentang pencahayaan alami pada kantor pemasaran ini membahas secara spesifik tentang faktor refleksi yang mempengaruhinya yaitu berkaitan dengan bentuk, warna, maupun tekstur bidang refleksi yang terdapat pada ruang penelitian. Penelitian ini masih dapat dikembangkan lebih lanjut untuk menemukan faktor-faktor lain yang dapat mempengaruhi pencahayaan alami, khususnya pada bangunan kantor. Selain itu, penelitian juga dapat 
dikembangkan dalam hubungan antara pencahayaan alami dengan kenyamanan termal bangunan kantor.

\section{DAFTAR PUSTAKA}

Alonso, Marcelo. (1992). Dasar-Dasar Fisika Universitas. Jakarta: Penerbit Erlangga.

Baker, Nick V. (1993). Daylighting in Architecture. London: Routledge.

Brown, G. Z. (1990). Matahari, Angin, dan Cahaya - Strategi Perancangan Arsitektur. Bandung: Intermatra.

Guzowski, Mary. (2000). Daylighing for Sustainable Design. United States of America: McGrawHill, Inc.

Lechner, N. (1991). Heating, Cooling, Lighting, Desing Methods for Architect. United States of America: John Willey and Sons Inc.

Lippsmeier, George. (1980). Building in The Tropics. Munchen: Callwey Verlag.

Mangunwijaya, Y. B., Dipl. Ing. (2000). Pasal-pasal Penghantar Fisika Bangunan. Jakarta: Djambatan. Manurung, Parmonangan. (2012). Pencahayaan Alami Dalam Arsitektur. Yogyakarta: ANDI.

Neufert, Ernst. (1996). Data Arsitek Jilid 1. Jakarta: Erlangga.

Satwiko, Prasasto. (2004). Fisika Bangunan 1 -Edisi 1. Yogyakarta: ANDI

Tim Penyusun. (2001). SNI 03-2396-2001 Tata Cara Perencanaan Sistem Pencahayaan Alami Pada Bangunan Gedung. Jakarta: Badan Standardisasi Nasional.

Tim Penyusun. (2001). SNI 03-6197-2000 Konservasi Energi pada Sistem Pencahayaan. Jakarta: Badan Standardisasi Nasional

Kompas. 2014. Kompas: Survei Membuktikan Pekerja yang Terkena Sinar Matahari Lebih Sejahtera. [Online]. http://properti.kompas.com/read/2014/12/12/160308421/Survei.Membuktikan.Pekerja.yang.T erkena.Sinar.Matahari.Lebih.Sejahtera. [15 Januari 2016].

http://sman1raha.sch.id/assets/main/images/download/150603194415751-2578-1-PB.pdf ., diakses 8 Febuari 2016

http://ruas.ub.ac.id/index.php/ruas/article/view/135., diakses 8 Febuari 2016

http://www.academia.edu/15364108/Optimalisasi_Pencahayaan_Alami_dalam_Efisiensi_Energi_di_ Perpustakaan_UGM ., diakses 8 Febuari 2016

http://tp3civil.blogspot.co.id/2012/02/pencahayaan-alami.html, diakses 10 Febuari 2016

http://viz.velux.com/daylight_visualizer/about, diakses 9 Maret 2016 